\title{
Considerações Sobre o Possível Papel do Cálcio, Ferro e Boro na Origem da Vida
}

Catarina Gonçalves

\begin{abstract}
Considerations on the Possible Role of Calcium, Iron, and Boron in the Origin of Life. Since Classical Antiquity, Humankind has been trying to understand how life could have been originated on Earth. The hypotheses proposed, usually, do not take into consideration the specific contribution of chemical elements. However, the scientific developments, over time, clarified the potential role of some chemical elements in this process, considering their specific reaction characteristics. In this article, within the scope of the International Year of the Periodic Table 2019, the relationship between three elements and some prebiotic reactions was analysed. It was chosen an alkaline earth metal (calcium), a transition metal (iron), and a semimetal (boron). Herein is considered the probable participation of these elements in the reactions leading to the synthesis of two of the main components for pre-biological evolution - ribose and nucleobases. Additionally, calcium and boron's role on ribose stabilization was analyzed.
\end{abstract}

Desde a Antiguidade Clássica que a Humanidade procura saber de que forma a vida terá surgido no planeta Terra. As hipóteses propostas não têm, tipicamente, em linha de conta o contributo específico dos elementos químicos. No entanto, os constantes avanços científicos têm permitido associar alguns elementos químicos a certas reações pré-biológicas, considerando para tal as especificidades reacionais daqueles. Neste artigo, no seguimento do Ano Internacional da Tabela Periódica 2019, descrevem-se três exemplos de elementos químicos que poderiam ter participado em algumas reações pré-bióticas. Foram escolhidos elementos de zonas distintas da Tabela Periódica, um metal alcalinoterroso (o cálcio), um metal de transição (o ferro) e um semimetal (o boro). Analisou-se a possível participação destes elementos na síntese de dois dos componentes fundamentais para a evolução pré-biológica - a ribose e as nucleobases. Adicionalmente, descreveu-se o papel do cálcio e do boro na estabilização da ribose.

\section{Introdução}

A origem da vida é um dos grandes mistérios da Humanidade. Desde a Antiguidade Clássica até à atualidade, diversas hipóteses [1] (como seja a geração espontânea, a Neopanspermia e o RNA World) têm vindo a ser propostas para explicar o aparecimento de seres vivos no planeta Terra.

0 desenvolvimento da Ciência tem permitido, ao longo do tempo, associar o contributo específico de alguns elementos químicos a estas hipóteses. Para que esta associação seja possível, é importante conhecer a composição química do Universo, da Terra atual e dos seres vivos, tentando, com estes dados, extrapolar qual seria a composição da Terra primitiva.

Atualmente, a análise dos elementos químicos presentes nos seres vivos pode funcionar como uma forma de compreender o passado, pois os elementos mais abundantes na Terra primitiva teriam sido, preferencialmente, incorporados nos organismos vivos, podendo ter tido um papel crucial nas primeiras reações pré-biológicas. Igualmente, o estudo da composição do Cosmos revela-se fundamental para conhecer a composição da Terra primitiva, sendo também interessante relacionar os elementos mais abundantes no Cosmos com os mais abundantes nos organismos vivos. A título de exemplo, veja-se a distribuição dos elementos no corpo humano. Este é constituído, 
em percentagem atómica, por hidrogénio - 62,8\%, oxigénio - $25,4 \%$, carbono - 9,4\% e nitrogénio - 1,4\%. 0 restante $1,0 \%$ é constituído por outros elementos [2]. No Cosmos, estes elementos pertencem ao grupo dos dez mais abundantes [3], constatando-se que o hidrogénio é, tal como nos seres vivos, o mais abundante, estando o carbono na sexta posição, logo seguido do nitrogénio e do oxigénio [3].

Nos seres vivos, elementos como o sódio, o potássio, o magnésio, o cálcio, o ferro, o fósforo, o enxofre e o cloro, apesar de existirem em baixas quantidades, são considerados essenciais para a vida, estando presentes em todos os sistemas biológicos [2]. Para além destes, elementos como o boro, o vanádio e o cromo são fundamentais para algumas espécies [2]. No Universo, estes elementos (com exceção do boro), não pertencem ao grupo dos dez mais abundantes [3].

As diferentes características reacionais dos elementos químicos, a par com a sua biodisponibilidade, poderão explicar a diferença que se verifica entre a sua abundância no Universo e nos organismos vivos [2]. Desta forma, revela-se pertinente analisar a contribuição individual de cada elemento químico no processo que conduziu à origem da vida.

Neste artigo, optou-se por analisar a importância pré-biológica de elementos químicos menos abundantes nos seres vivos. Escolheu-se um metal alcalinoterroso, o cálcio, um metal de transição, o ferro, e um semimetal, o boro. A Figura 1 apresenta a localização de cada um destes elementos na Tabela Periódica.

O cálcio é o $20{ }^{\circ}$ elemento mais abundante no Universo [3]. Em solução aquosa ocorre na forma de ião dipositivo [5]. 0 ferro é o 26. elemento mais abundante no Cosmos [3], podendo, em solução aquosa, originar catiões com carga +2 ou +3 . Por fim, o boro é o $5 .^{\circ}$ elemento mais abundante no Universo [3].

Começar-se-á com uma contextualização histórica das hipóteses da origem da vida, dando-se ênfase à hipótese mais aceite, atualmente, nos meios científicos - a hipótese do RNA World [6]. Na terceira secção deste artigo, descrever-se-á a síntese e estabilização da ribose, ao passo que na quarta secção serão abordadas algumas reações que poderão ter permitido a síntese de nucleobases na Terra primitiva. Os elementos selecionados serão relacionados com estes processos reacionais, terminando-se, na quinta secção, com algumas considerações gerais sobre o seu possível papel no processo de origem da vida.

\section{Hipóteses para explicar a origem da vida}

\subsection{Breve contextualização histórica}

As estimativas atuais indiciam que a Terra ter-se-á formado há aproximadamente 4,6 mil milhões de anos [7]. 0 momento do aparecimento de vida não é, ainda, consensual. Alguns autores situam-no há

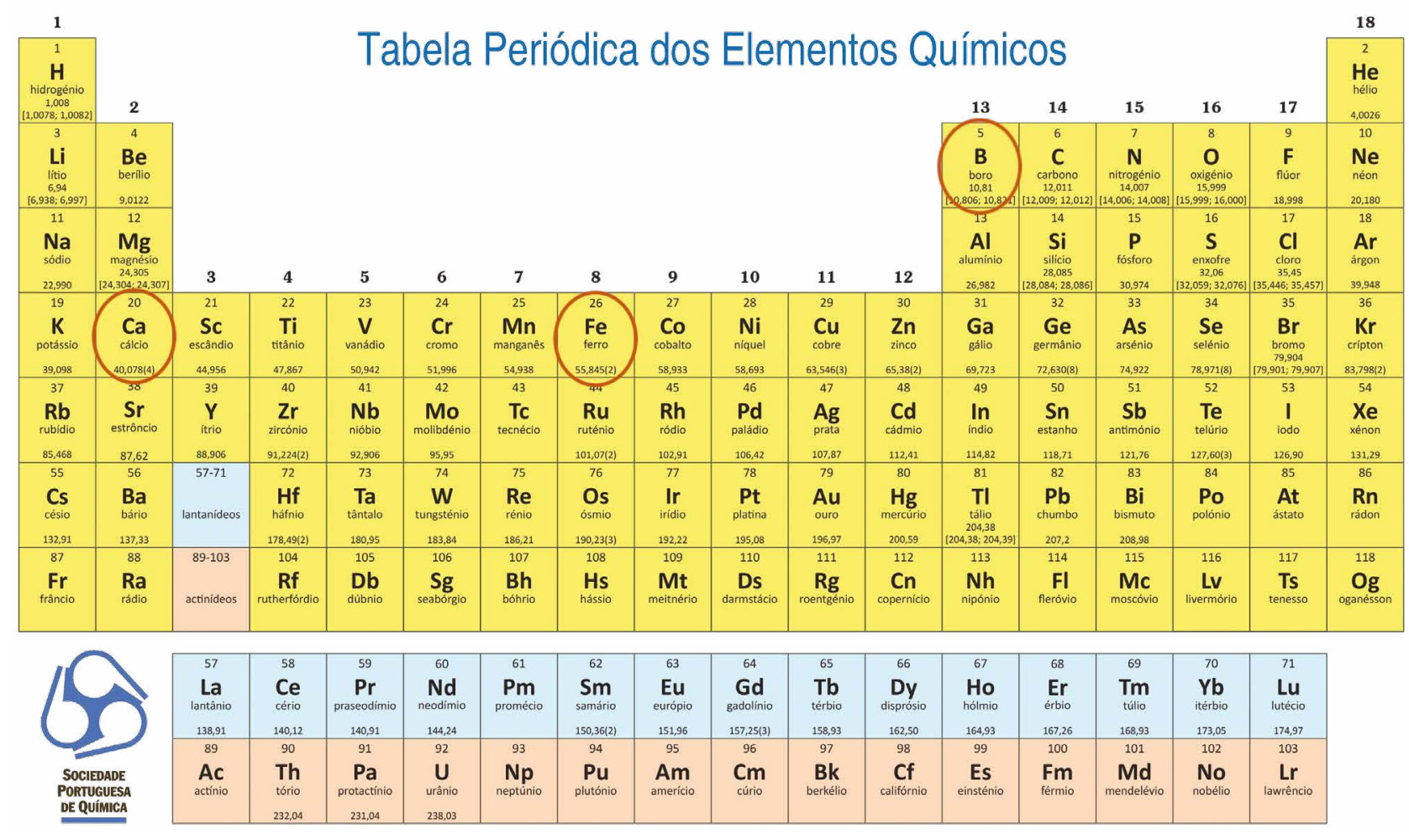


3,5 mil milhões de anos [8], ao passo que outros admitem que pode ter ocorrido mais cedo, entre os 4,1 e os 4,2 mil milhões de anos [7].

Aristóteles propôs aquela que se considera a primeira hipótese de origem da vida. Segundo este autor [1], a vida ter-se-ia originado por geração espontânea, hipótese que só começou a ser posta em causa no século XIX, com as experiências de Pasteur [9]. Estas conduziram ao estabelecimento das primeiras hipóteses científicas para a origem da vida.

Em 1908, Arrhenius [10] apresentou a hipótese da Panspermia, segundo a qual a vida teria surgido algures no Cosmos. Posteriormente, os seres vivos teriam sido transportados, por corpos celestes, até à Terra. No entanto, seria improvável que conseguissem sobreviver nas condições inóspitas do espaço cósmico. Assim, surge, mais tarde, a Neopanspermia, que admite a hipótese dos corpos celestes terem transportado alguns dos blocos fundamentais que viriam, posteriormente, a originar os seres vivos $[7,11,12]$. Nesta hipótese, pressupõe-se que estes blocos teriam chegado à Terra no período conhecido como Late Heavy Bombardment (ou Período de Intenso Bombardeamento Tardio, em português), que teria ocorrido entre os 3,8 e os 4,0 mil milhões de anos [7]. Nesta altura, a Terra teria sido bombardeada com material proveniente da cintura de asteroides, como resultado da migração dos planetas gasosos [13]. É discutível se a matéria orgânica transportada por esta via poderia ter mantido a sua integridade, após o impacto, permitindo gerar estruturas prébiológicas. Alguns autores [11] consideram que o aumento de temperatura resultante do impacto poderia ter promovido a degradação da matéria orgânica presente na superfície destes corpos celestes. Já a matéria localizada no interior do meteorito, caso tivesse sido preservada após o impacto, teria de migrar para o exterior com vista a contribuir para a origem da vida, o que é considerado pouco provável [11]. Porém, existem evidências da presença de nucleobases e monossacarídeos (constituintes fundamentais do RNA) em condritos carbonáceos [14], o tipo mais primitivo de meteorito [15]. Desta forma, serão necessários mais estudos neste campo para aferir a possibilidade de os meteoritos terem transportado para a Terra os blocos fundamentais que contribuíram para a génese da vida. É igualmente fundamental compreender de que forma estes compostos poderiam ter sido gerados no Cosmos (na quarta secção deste artigo apresenta-se uma hipótese de síntese na nebulosa solar).

No século XX, Oparin [12] e Haldane [16] propuseram, de forma independente, a hipótese de a vida ter resultado de reações químicas entre uma mistura de moléculas pequenas. Nesta hipótese considera-se relevante o papel da radiação solar e da atmosfera com caráter redutivo [7]. Mais tarde, os trabalhos experimentais de Miller, quer como autor único [17], quer conjuntamente com Urey [18], vieram dar alguma credibilidade a esta hipótese. Nas experiências realizadas, os autores simularam a atmosfera primitiva, recorrendo para tal a metano $\left(\mathrm{CH}_{4}\right)$, amoníaco $\left(\mathrm{NH}_{3}\right)$, água $\left(\mathrm{H}_{2} \mathrm{O}\right)$ e hidrogénio molecular $\left(\mathrm{H}_{2}\right)$, bem como a descargas elétricas, tendo obtido, ao fim de alguns dias, aminoácidos (maioritariamente glicina e alanina, esta última, tanto na forma $\alpha$, como na forma $\beta$ ) [17].

Para concluir esta contextualização histórica, é ainda importante referir duas hipóteses baseadas em sistemas de ferro-enxofre (pois o ferro é um dos elementos em destaque neste artigo).

A hipótese do mundo de ferro-enxofre $[19,20]$, bem como a hipótese membranar de ferro-enxofre [21] foram propostas em 1988. Ambas sugerem que a vida se teria iniciado em fluidos hidrotermais graças às reações entre sulfuretos de metais de transição, principalmente de ferro.

A hipótese do mundo de ferro-enxofre, proposta por Wächtershäuser $[19,20]$, admite que a reação primordial consistiria na formação de pirite $\left(\mathrm{FeS}_{2}\right)$ e de $\mathrm{H}_{2}$, partindo para tal de ácido sulfídrico $\left(\mathrm{H}_{2} \mathrm{~S}\right)$ e troilita (FeS). Esta reação teria ocorrido em meio aquoso, o que permitiria a reação de $\mathrm{H}_{2}$ com dióxido de carbono $\left(\mathrm{CO}_{2}\right)$ dissolvido no meio, originando assim ácido fórmico $(\mathrm{HCOOH})$. Adicionalmente, $\mathrm{o}_{2}$ poderia atuar como agente redutor dos óxidos de carbono, o que teria favorecido a produção de algumas biomoléculas [20], como se evidencia na Figura 2.

Já a hipótese membranar de ferro-enxofre,

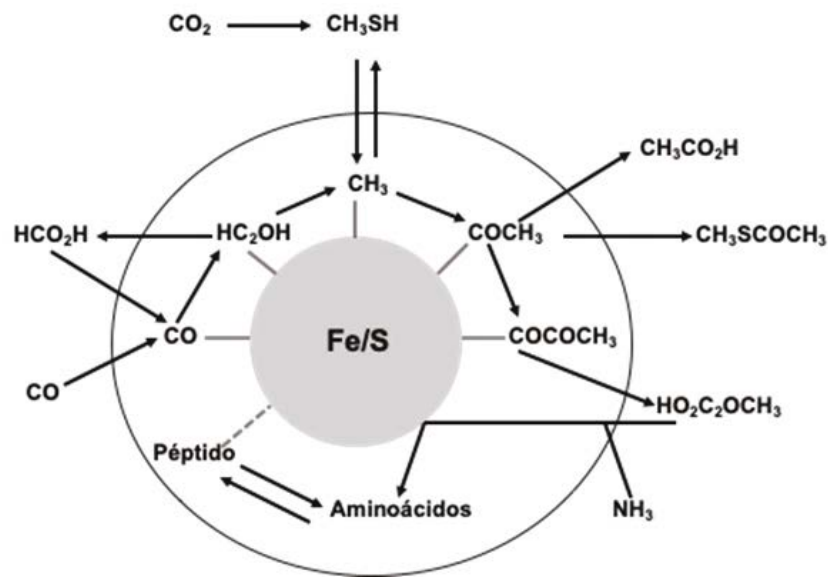

Figura 2 - Reações possíveis para os sistemas pré-biológicos de acordo com a hipótese do mundo de ferro-enxofre. Adaptada da referência [12]. 
proposta por Russell [21] (e cuja representação esquemática pode ser encontrada na Figura 3), admite que as reações primordiais teriam ocorrido graças à interação dos fluidos hidrotermais com os oceanos primitivos, o que teria permitido a precipitação dos sulfuretos de metais de transição, principalmente de ferro, que teriam, por seu turno, favorecido a formação de estruturas membranares com caráter hidrofóbico. Estas teriam possibilitado a separação do ambiente interior (caracterizado por um ambiente redutor e $\mathrm{pH}$ elevado) do exterior. $\mathrm{O}$ gradiente de $\mathrm{pH}$ entre os dois ambientes, aliado ao gradiente de potencial, teria favorecido a transferência eletrónica, bem como a entrada de $\mathrm{CO}_{2}$, com a consequente formação de biomoléculas, num processo análogo ao proposto por Wächtershäuser [21].

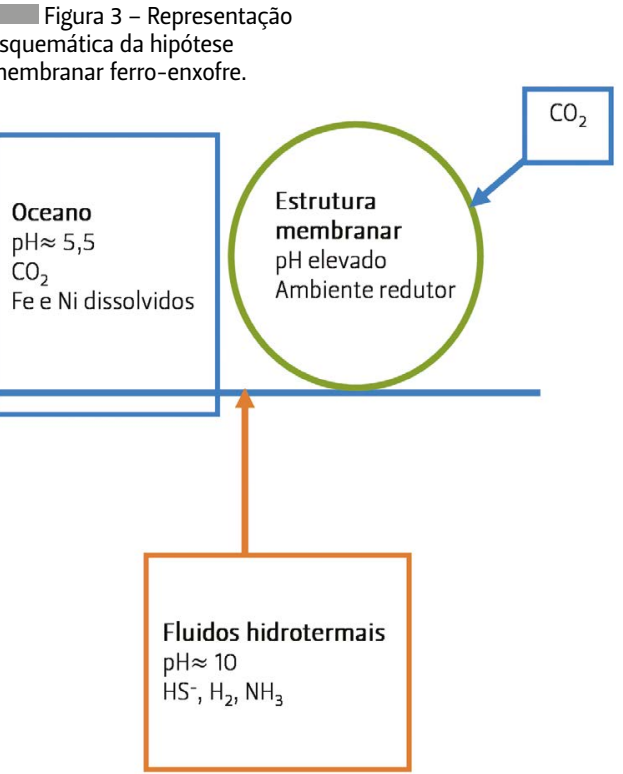

\subsection{Hipótese do RNA World}

Nesta hipótese, proposta pela primeira vez em 1962 [22], admite-se que o ácido ribonucleico (ou RiboNucleic Acid - RNA) ter-se-ia formado, no ambiente terrestre primitivo, antes do ácido desoxirribonucleico (DeoxyriboNucleic Acid - DNA). O RNA teria funcionado como forma de armazenar informação genética, permitindo a síntese proteica, e, simultaneamente, teria atuado como catalisador reacional na forma de ribozima $[23,24]$.

Tanto o RNA [25] como o DNA são cadeias com carácter polimérico que resultam da reação entre diversos nucleótidos. Estes, por seu turno, são constituídos por uma pentose, uma nucleobase e um grupo fosfato. No RNA, o monossacarídeo utilizado é a ribose, ao passo que no DNA é a desoxirribose. A ribose é uma molécula que pode adotar duas formas cíclicas, que se apresentam na Figura 4, a forma de furanose (1) ou a de piranose (2). A primeira caracteriza-se por um anel de cinco membros, ao passo que a segunda apresenta um anel de seis membros.
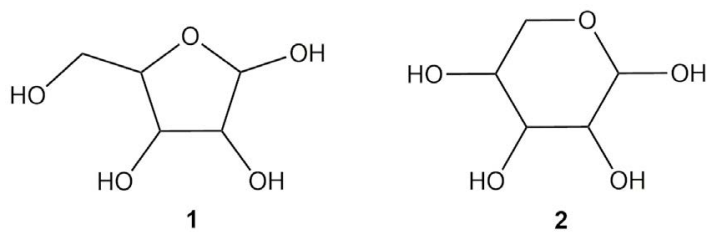

Figura 4 - Formas cíclicas adotadas pela ribose: furanose (1) e piranose (2).

A ribose, no estado sólido e em solução aquosa, ocorre, tipicamente, na forma de piranose. Já nos seres vivos, nas estruturas em que está presente, encontra-se na forma de furanose [26]. Existem cinco nucleobases associadas aos ácidos nucleicos: a adenina, a guanina, a citosina, a timina e o uracilo. As três primeiras são características tanto do DNA como do RNA, ao passo que a timina é exclusiva do ácido desoxirribonucleico e o uracilo é exclusivo do ácido ribonucleico. Na Figura 5 encontra-se a representação esquemática destas nucleobases.

Figura 5 - Representação esquemática das nucleobases associadas aos ácidos nucleicos: adenina (3), guanina (4), citosina (5), uracilo (6) e timina (7).<smiles>Nc1ncnc2nc[nH]c12</smiles>

3<smiles>Nc1cc[nH]c(=O)n1</smiles><smiles>Nc1nc2[nH]cnc2c(=O)[nH]1</smiles>

4
Para que o RNA se formasse, no ambiente terrestre primitivo, seria necessária a síntese, numa primeira instância, dos seus três constituintes fundamentais e a posterior reação entre si, de forma a 
originar ribonucleótidos. Na Figura 6 encontra-se a representação esquemática de um ribonucleótido, o 5'-monofosfato de adenosina.

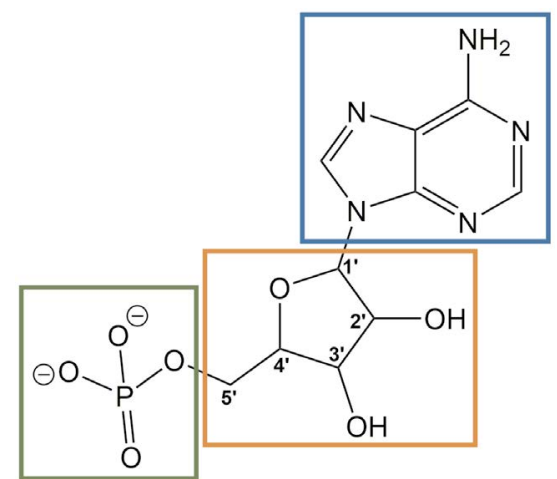

Figura 6 - Representação esquemática do 5'-monofosfato de adenosina (azul - adenina; laranja - ribose; verde - grupo fosfato). Os hidrogénios da ribose foram omitidos para facilitar a leitura.

A observação da figura permite verificar que se estabelece uma ligação $N$-g'licosídica entre um dos átomos de nitrogénio do anel de imidazole da adenina e o carbono anomérico (C1') da ribose. Adicionalmente, o grupo fosfato estabelece uma ligacção 0-ǵlicosídica com o carbono 5' do monossacarídeo. Nos restantes ribonucleótidos a ligação é análoga, verificando-se apenas a alteração da nucleobase.

Em seguida, será analisada a forma como os elementos selecionados (cálcio, ferro e boro) poderiam ter contribuído para as reações que favoreceram a síntese da ribose e das nucleobases no ambiente terrestre primitivo. Será também descrita a forma como dois destes elementos (cálcio e boro) contribuem para a estabilização da ribose.

A síntese da ribose e das nucleobases, bem como a síntese dos ribonucleósidos e dos ribonucleótidos já se encontra documentada na literatura [7]. Uma vez que o principal objetivo do presente artigo é relacionar os elementos selecionados com algumas reações pré-bióticas e, admitindo que a síntese dos ribonucleósidos e dos ribonucleótidos ocorreu graças à reação direta entre os seus constituintes fundamentais, optou-se por analisar somente a influência dos elementos selecionados em algumas reações que poderiam ter permitido a síntese destes constituintes, isto é, a ribose e as nucleobases.

\section{Ribose}

A ribose é uma molécula pouco estável, apresentando a pH 7 e $100{ }^{\circ} \mathrm{C}$, um tempo de semivida de apenas 73 minutos [12]. Desta forma, a sua síntese no ambiente terrestre primitivo pressupõe a sua consequente estabi- lização, com vista a levar a cabo reações mais complexas, como as que teriam originado os ribonucleótidos. Nesta secção, analisa-se a forma como os elementos químicos selecionados poderiam ter contribuído para a síntese e estabilização da ribose na Terra primitiva.

\subsection{Síntese}

As condições da Terra primitiva eram consideravelmente diferentes das que conhecemos hoje [26], sendo portanto necessário estudar as possíveis reações de síntese em condições admissíveis nesse período. Este trabalho é muitas vezes especulativo, na medida em que há pouca informação do período em causa.

Admite-se que a síntese dos monossacarídeos, particularmente da ribose, no ambiente terrestre primitivo, teria ocorrido a partir do formaldeído $\left(\mathrm{CH}_{2} \mathrm{O}\right)$ [27], num processo conhecido como reação da formose [28]. É admissível que esta reação esteja de acordo com as condições geoquímicas da Terra primitiva [29].

É preciso compreender, numa primeira instância, como se teria formado o formaldeído na Terra primitiva. Este composto pode ser obtido, quer pela fotorredução do $\mathrm{CO}_{2}$, quer através de eletrorredução [27], estando esta última hipótese em consonância com as experiências de Miller-Urey. Na Figura 7 apresentam-se alguns passos da reação da formose. Note-se que esta reação ocorre tipicamente para temperaturas na ordem dos $100{ }^{\circ} \mathrm{C}$ e requer um $\mathrm{pH}$ elevado [27].

Figura 7 - Reação da formose. Adaptada da referência [27].

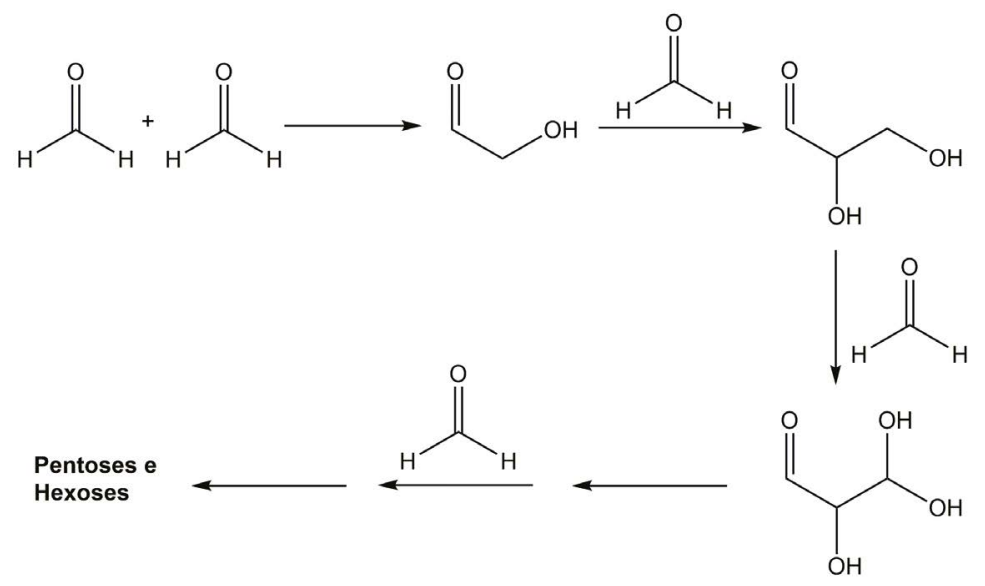

Um dos grandes problemas da reação da formose prende-se com a rápida degradação dos produtos, o que poderia ter impedido a acumulação dos mesmos, não permitindo, desta forma, a realização de reações subsequentes [27]. As pentoses e hexoses são, tipicamente, mais estáveis do que os monossacarídeos com menor número de átomos de carbono, sendo esses os 
produtos preferenciais deste processo reacional. Ainda assim, tendem a degradar-se ao fim de algum tempo [27], o que justifica a necessidade de garantir a sua estabilização no ambiente terrestre primitivo.

A utilização de catalisadores neste processo reacional permitiria um aumento da velocidade da reação. Este aumento de velocidade poderia favorecer a acumulação de produtos no meio ou o seu uso imediato em reações subsequentes, suplantando assim a sua degradação. Uma hipótese passaria por recorrer a sais presentes na Terra primitiva para esta função, não se invalidando ainda assim a estabilização dos produtos resultantes da reação da formose (assunto a abordar em maior detalhe na secção 3.2.).

0 hidróxido de cálcio é um sal com elevada atividade catalítica [27], que tem vindo a ser estudado como possível catalisador da reação da formose [29,30]. Já existem evidências laboratoriais da sua possível ação catalítica nesta reação [31]. No entanto, é de notar que as experiências laboratoriais realizadas para obter ribose recorrendo a este processo reacional foram efetuadas com pHs entre 10 e 11 e temperaturas entre os 60 e os $80{ }^{\circ} \mathrm{C}$ [32]. 0 facto da temperatura reacional, na presença de catalisador, ser ligeiramente inferior à temperatura na sua ausência, poderia ter facilitado a ocorrência desta reação no ambiente terrestre primitivo. As condições laboratoriais utilizadas podem ser consideradas consistentes com o ambiente pré-biológico [33]. No entanto, o pH elevado a que se recorreu poderá apresentar desvantagens na medida em que as pentoses nestas condições tendem a degradar-se facilmente [34].

A relação do cálcio com a reação da formose não se fica pelo hidróxido de cálcio. Na realidade, também o carbonato de cálcio pode atuar como catalisador desta reação [35,36]. As evidências de um estudo de 1993 [29] permitiram concluir que, na reação da formose, o cálcio não é essencial para a obtenção dos produtos, inferindo-se assim que tem uma ação meramente catalítica. Este papel é adicionalmente justificado pelo facto de os sais apresentados como exemplo serem constituídos por aniões diferentes, apresentando como fator comum apenas o catião cálcio.

Ao longo do tempo, a comunidade científica tem vindo a debater a possibilidade da reação da formose ter originado ribose no mundo pré-biológico [27,29]. É importante notar que nem todas as reações plausíveis do ponto de vista teórico (e executáveis em laboratório) correspondem a reações pré-bióticas que ocorreram na realidade, sendo, portanto, necessário continuar a estudar esta área da Química.

\subsection{Estabilização}

Tal como foi referido no início desta secção, a ribose é uma molécula pouco estável, o que se comprova pelas evidências da sua degradação quando em presença de carbonato [36]. Uma vez que este anião estaria presente na água do mar na Terra primitiva [37], a estabilização da ribose teria sido crucial para permitir a síntese de estruturas mais complexas. Os estudos atuais indiciam que quer o cálcio, quer o boro poderiam ter participado na estabilização deste monossacarídeo.

\subsubsection{Cálcio}

O cálcio tem um papel fundamental na estabilização da ribose na forma de furanose. Esta estabilização resulta da coordenação do cloreto de cálcio com a furanose, no estado sólido [38]. A coordenação ocorre graças às ligações relativamente fortes que o ião cálcio pode estabelecer com os monossacarídeos [39].

Na Figura 8 ilustra-se, esquematicamente, a coordenação do ião cálcio com a ribose. Este ião coordena-se com duas moléculas de ribose e, simultaneamente, com três moléculas de água. A coordenação ocorre através dos átomos de oxigénio. No caso da ribose, o cálcio coordena-se com os oxigénios ligados aos carbonos 1', 2' e 3' (cf. Figura 6) de uma molécula de ribose e os oxigénios ligados aos carbonos 4' e 5' de outra molécula de monossacarídeo. As ligações podem ter comprimento entre 2,368 e 2,538 $\AA$ [38].

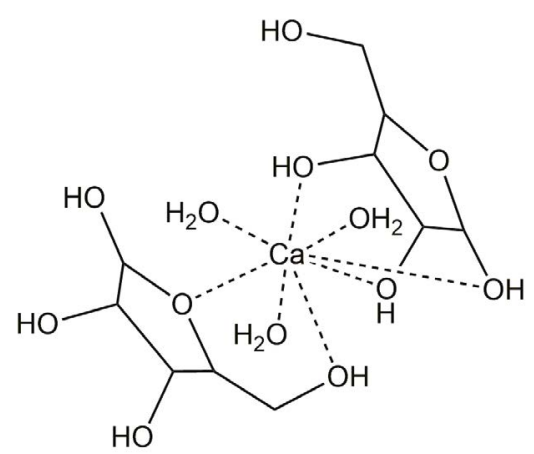

Figura 8 - Representação esquemática da coordenação do cálcio com a ribose. Adaptada da referência [38].

Os lantanídeos apresentam raios iónicos análogos aos do cálcio, podendo também coordenar-se com a ribose. No entanto, esta coordenação ocorre somente quando a ribose se encontra na forma de piranose [40-43], sendo a estabilização na forma de furanose, por ação de um catião, exclusiva do cálcio.

\subsubsection{Boro}

O boro, na forma de borato, é o único anião capaz de estabilizar a ribose na forma de furanose [44-46] em meio aquoso [47]. Esta estabilização poderia ter ocorrido em associação com a reação da formose, sendo uma propriedade particularmente importante, 
na medida em que poderia ter facilitado a acumulação da ribose no ambiente terrestre primitivo [45].

0 borato pode formar, com a ribose, ésteres com estequiometria 1:1 ou 1:2. A ligação ocorre tipicamente entre os carbonos 2' e 3' do monossacarídeo (consultar numeração na Figura 6) e o borato. Desta forma, os carbonos 1' e 5' da ribose, permanecem livres para a adição dos restantes constituintes dos ribonucleótidos $[43,46]$. Na Figura 9 ilustra-se a ligaçãa entre o borato e a ribose na proporção 1:2.

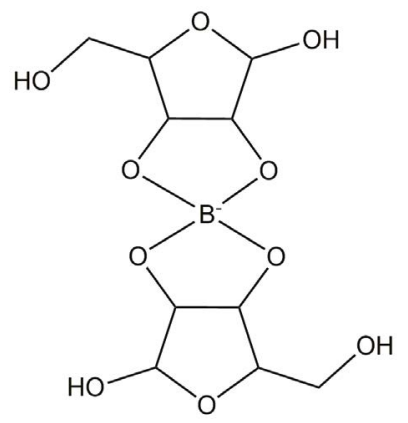

Figura 9- Representação esquemática da ligaç̧ão entre o borato e a ribose (1:2).

Existem já estudos, quer experimentais [48] quer computacionais [49], que comprovam a ação do borato como estabilizador da ribose. Ao nível experimental [48], comprovou-se que o aumento da concentração de borato conduz ao aumento de estabilidade do monossacarídeo. Já o estudo teórico [49] veio fundamentar as evidências de que os ésteres de ribose-borato são mais estáveis do que os ésteres de borato com outras pentoses (como seja a arabinose, lixose e xilose), o que fundamenta o uso preferencial deste monossacarídeo nas estruturas pré-biológicas.

0 boro pode igualmente estabilizar a ribose, em meio ácido, sendo neste caso utilizado na forma de ácido bórico $[36,50]$.

\section{Síntese das nucleobases}

Para além do estudo da forma como a ribose poderia ter sido sintetizada no ambiente terrestre primitivo, é importante compreender como se poderiam ter formado neste ambiente as nucleobases. Nesta secção apresentam-se exemplos da participação do cálcio e do ferro em algumas reações que poderiam ter conduzido à síntese de nucleobases.

\subsection{Reação da formamida}

A reação da formamida, representada esquematicamente na Figura 10, encontra-se bem documentada na literatura [51-53]. Esta reação tem sido utilizada para obter quer purinas quer pirimidinas em condições pré-biológicas. Uma vez que a formamida já foi detetada no Cosmos, este composto é considerado um possível reagente pré-biológico [54].

Figura 10 - Reação da formamida (8) originando adenina $(3)$, citosina (5), purina (9) e pirimidin-4(3H)-ona (10).<smiles>NC=O</smiles>

8<smiles>Nc1ncnc2[nH]cnc12</smiles><smiles>c1ncc2[nH]cnc2n1</smiles>

9<smiles>Nc1cc[nH]c(=O)n1</smiles><smiles>O=c1ccnc[nH]1</smiles>

Os cientistas têm estudado diversas hipóteses de catalisadores para esta reação, tentando perceber quais os minerais mais adequados, na Terra primitiva, à obtenção dos produtos desejados em quantidades que permitissem a síntese dos ribonucleótidos.

Em 2000 [55], utilizando o carbonato de cálcio como catalisador, verificou-se um aumento de 530\% na obtenção de purina em relação à reação sem catalisador. Mais recentemente, em 2010 [56], comprovou-se que o uso deste sal como catalisador, permite, ainda, aumentar a quantidade de adenina obtida a partir da mesma reação.

O ferro, à semelhança do cálcio, poderia ter participado como catalisador na reação ilustrada na Figura 10. Neste caso, o ferro encontrar-se-ia na forma mineral como $\mathrm{FeS}_{2}$ ou calcopirite $\left(\mathrm{FeCuS}_{2}\right.$ ), por exemplo [57]. A pirite teria sido um mineral abundante no período pré-biológico, sendo adicionalmente um componente importante da hipótese do mundo de ferro-enxofre [57]. Os estudos laboratoriais realizados utilizando minerais de ferro como catalisadores da reação da formamida revelaram que a tetraedrite, $(\mathrm{Cu}, \mathrm{Fe})_{12} \mathrm{Sb}_{4} \mathrm{~S}_{13}$, [57] permitiu um aumento de 9,8\% na obtenção de purina em relação à reação não catalisada. Adicionalmente, estudos que recorreram a olivinas (minerais de ferro, magnésio e silicatos) como catalisadores permitiram obter citosina e pirimidin-4(3H)-ona a partir da mesma reação [58], produtos estes que não tinham sido obtidos na ausência de catalisador. 


\subsection{Reação de fotodesidrogenação do DHU} A reação de fotodesidrogenação do DHU (5,6-di-hidrouracilo) é uma reação que poderia ter permitido a obtenção de uracilo no mundo pré-biológico. A representação esquemática desta reação está presente na Figura 11. Nas experiências laboratoriais, o DHU foi obtido, numa primeira instância, graças à reação entre a $\beta$-alanina e a ureia (possíveis reagentes pré-biológicos) [59].

Figura 11 - Reação de

fotodesidrogenação do DHU a uracilo.<smiles>O=C1CCNC(=O)N1</smiles>

De entre os elementos selecionados neste artigo, o cálcio, na forma de carbonato, foi utilizado em 1976 [59] como possível catalisador desta reação. No entanto, a utilização deste sal permitiu a obtenção de um rendimento de apenas $2 \%$, valor este que é bastante baixo quando comparado com o de outros catalisadores (como seja a montmorilonite, argilo-mineral constituído por dióxido de silício, alumínio e oxigénio). Conclui-se assim que, provavelmente, este sal não teria atuado como catalisador na reação descrita. No entanto, os processos reacionais no mundo pré-biológico poderiam ter decorrido ao longo de milhares de anos, por isso o baixo rendimento poderia não ser problemático. Desta forma, serão necessários mais estudos para perceber se o carbonato de cálcio poderia ter contribuído de alguma forma para este processo reacional.

\subsection{Possíveis sínteses na nebulosa solar}

Tal como descrito anteriormente (ver ponto 2.1.), a hipótese da Neopanspermia pressupõe a síntese dos blocos fundamentais no Cosmos. Uma possibilidade seria sintetizar estes compostos na nebulosa solar. Nesta secção, analisa-se o papel que os elementos selecionados poderiam ter desempenhado nas referidas sínteses. Note-se ainda que a presença de nucleobases e monossacarídeos em condritos carbonáceos $[14,15]$ indicia que estes compostos poderiam ter sido transportados até à Terra pelos corpos celestes.

Existem já estudos que sugerem que os compostos de nitrogénio (nomeadamente as purinas) poder-se-iam ter formado graças a reações envolvendo $\mathrm{CO}_{2}, \mathrm{H}_{2}$ e NH $\mathrm{N}_{3}$, $\mathrm{O}$ que fundamentaria a síntese deste tipo de compostos na nebulosa solar. Nas experiências laboratoriais realizadas neste campo recorreu-se aos meteoritos Orgueil e Murray [60]. Estes foram pulverizados, tendo o pó resultante sido utilizado como catalisador reacional. Este pó continha, entre outros compostos, ferro [61], o que indicia a importância deste elemento para as sínteses na nebulosa solar. Foi possível assim fundamentar a hipótese da génese dos blocos fundamentais ter ocorrido na nebulosa solar [62] por reações espontâneas. Reações similares foram realizadas em 1971 recorrendo neste caso a catalisadores de ferro e níquel [63]. Nos ensaios laboratoriais descritos, admitiu-se que a síntese dos compostos de nitrogénio teria ocorrido graças a reações de Fischer-Tropsch, reações que permitem obter hidrocarbonetos líquidos a partir de monóxido de carbono (CO) e $\mathrm{H}_{2}$ gasosos. Esta é uma alternativa apresentada para explicar o processo reacional na nebulosa solar, pois as sínteses de Miller-Urey não permitem obter, entre outros, os hidrocarbonetos alifáticos e aromáticos, os anéis heterocíclicos de nitrogénio e vários compostos contendo oxigénio [64].

\section{Considerações finais}

A origem da vida constitui uma das maiores questões da Humanidade. 0 desenvolvimento da Ciência tem permitido, ao longo dos séculos, formular novas hipóteses para tentar dar respostas mais completas e satisfatórias a esta questão. No entanto, a dificuldade em reproduzir as condições da Terra primitiva, aliada à dificuldade de obtenção de amostras desse período não permitiu ainda perceber inequivocamente de que forma a vida teria surgido no planeta Terra. A análise detalhada dos elementos químicos e das suas propriedades poderá ser fundamental para compreender os mecanismos reacionais no ambiente pré-biológico, sendo, portanto, necessário continuar a estudar esta área da Química.

A análise aqui efetuada do possível papel do cálcio, ferro e boro na origem da vida indicia que estes elementos são bastante versáteis, na medida em que poderão ter participado em algumas reações pré-biológicas com natureza distinta. 0 cálcio e o boro podem ter sido importantes para a síntese e estabilização da ribose, ao passo que o ferro poderá ter atuado como catalisador na síntese das nucleobases. Neste processo reacional é também de destacar a possível ação catalítica do cálcio.

\section{Agradecimentos}

Agrradeço ao Professor José Armando Luísa da Silva o apoio e as sugestões de melhoria do texto deste artigo.

\section{Referências}

[1] L. T. Ackert, "History of Origins of Life, Encyclopedia of Evolutionary Biology", 181-185, Elsevier, Pennsylvania, 2016

[2] J. J. R. Fraústo da Silva, R. J. P. Williams, "The biological chemistry of the elements - The inorganic chemistry of life", Oxford University Press, $2^{\text {nd }}$ ed. Oxford, 2001. 
[3] A. G. W. Cameron, Space Sci. Rev. 1970, 15, 121-146. DOI: 10.1007/ BF00172440.

[4] Tabela Periódica SPQ [Online]: spq.pt/files/files/tabela_periodica.pdf (Acedido em 06/02/2020).

[5] J. Kazmierczak, S. Kempe, B. Kremer, Curr. Org. Chem. 2013, 17, 1738-1750. DOI: 10.2174/13852728113179990081.

[6] A. Lazcano, BIO Web Conf. 2015, 4, 00013. DOI: 10.1051/bioconf/20150400013.

[7] N. Kitadai, S. Maruyama, Geosci. Front. 2018, 9, 1117-1153. DOI: 10.1016/j. gsf.2017.07.007.

[8] P. G. Higgs, "RNA World and Origin of life", Encyclopedia of Evolutionary Biology, 175180, Elsevier, Pennsylvania, 2016.

[9] B. L. Ligon, Semin. Pediatr. Infect. Dis. 2002, 13, 134-141. DOI: 10.1053/ spid.2002.125138

[10] S. Arrhenius, "Worlds in the making - The evolution of the universe", Harper \& Brothers, 1903

[11] S. Maruyama, K. Kurokawa, T. Ebisuzaki, Y. Sawaki, K. Suda, M. Santosh, Geosci. Front. 2019, 10, 1337-1357. DOI: 10.1016/j.gsf.2018.09.011.

[12] A. I. Oparin, H. Abreu, S. Tirard, A. F. Amaral, J. A. L. da Silva, J. M. Torres, A. L. Araujo, M. Cachão, T. Rodrigues, L. Pereira, F. Carrapiço, R. J. Agostinho, G. V. Levin, "Vida - Origem e evolução", Esfera das Ciências, Lisboa, 2011.

[13] J. Bailey, Proceedings of the $6^{\text {th }}$ Australian Space Science Conference 2006, 17-22. Disponível em: citeseerx.ist.psu.edu/viewdoc/ download?doi=10.1.1.518.7146\&rep=rep1\&type $=$ pdf

[14] Y. Furukawa, Y. Chikaraishi, N. Ohkouchi, N. O. Ogawa, D. P. Glavin, J. P. Dworkin, C. Abe, T. Nakamura, Proc. Natl. Acad. Sci. U. S. A. 2019, 116, 24440-24445. DOI: 10.1073/pnas.1907169116.

[15] A. S. Burton, J. C. Stern, J. E. Elsila, D. P. Glavin, J. P. Dworkin, Chem. Soc. Rev. 2012, 41, 5459-5472. DOI: 10.1039/C2CS35109A.

[16] J. B. S. Haldane, Origin of Life. The Rationalist Annual 1929, 148, 3-10. Disponível em: uv.es/ orilife/textos/Haldane.pdf

[17] S. L. Miller, Science 1953, 117, 528-529. DOI: 10.1126/science.117.3046.528.

[18] S. L. Miller, H. C. Urey, Science 1959, 130, 245-251. DOI: 10.1126/ science.130.3370.245

[19] G. Wächtershäuser, Microbiol. Rev. 1988, 52, 452-484. ncbi.nlm.nih.gov/ pmc/articles/PMC373159.

[20] G. Wächtershäuser, Syst. Appl. Microbiol. 1988, 10, 207-210. DOI: 10.1016/ S0723-2020(88)80001-8.

[21] M. J. Russell, A. J. Hall, A. G. Cairnssmith, P. S. Braterman, Nature 1988, 334, 609611. DOI: 10.1038/334609a0.

[22] P. M. Perrigue, V. A. Erdmann, J. Barciszewski, Trends Biochem. Sci. 2015, 40 623624. DOI: 10.1016/j.tibs.2015.08.009

[23] T. R. Cech, Gene 1993, 135, 33-36. DOI: 10.1016/0378-1119(93)90046-6.

[24] T. R. Cech, Proc. Natl. Acad. Sci. U. S. A. 1986, 83, 4360-4363. DOI: 10.1073/pnas.83.12.4360.

[25] S. Clancy, Chemical structure of RNA, Nature Education 2008. Disponível em: nature.com/scitable/topicpage/chemical-structure-of-rna-348 (Acedido em 08/07/2019).

[26] P. Pontarotti, Evolution, "Origin of Life, Concepts and Methods", Springer, Marseille, 2019.

[27] D. Kopetzki, M. Antonietti, New J. Chem. 2011, 35, 1787-1794. DOI: 10.1039/ C1NJ20191C.

[28] A. Butlerow, Compt. Rend. Acad. Sci. 1861, 53, 145-147. [online]: biodiversitylibrary.org/item/23712\#page/150/mode/1up.

[29] A. W. Schwartz, R. M. de Graaf, J. Mol. Evol. 1993, 36, 101-106. DOI: 10.1007/ BF00166245.

[30] L. Burroughs, P. A. Clarke, H. Forintos, J. A. R, Gilks, C. J. Hayes, M. E. Vale, W. Wade, M. Zbytniewski, Org. Biomol. Chem. 2012, 10, 1565-1570. DOI: 10.1039/C10B06798B.

[31] H. J. Kim, A. Ricardo, H. I. Illangkoom, M. J. Kim, M. A. Carrigan, F. Freye, S. A. Benner, J. Am. Chem. Soc. 2011, 133, 9457-9468. D0l: 10.1021/ja201769f

[32] S. A. Benner, H. J. Kim, M. A. Carrigan, Acc. Chem. Res. 2012, 45, 20252034. DOl: 10.1021/ar200332w.

[33] N. H. Sleep, D. K. Bird, E. C. Pope, Philos. Trans. R. Soc. B Biol. Sci. 2011, 366, 2857-2869. DOI:10.1098/rstb.2011.0129.

[34] C. Reid, L. E. Orgel, Nature 1967, 216, 455. DOI: 10.1038/216455a0.

[35] A. G. Cairns-Smith, P. Ingram, G. L. Walker, J. Theor. Biol. 1972, 35, 601-604 DOI: 10.1016/0022-5193(72)90153-1.

[36] A. F. Amaral, M. M. Marques, J. A. L. da Silva, J. J. R. Fraústo da Silva, New J. Chem. 2008, 32, 2043-2049. DOl: 10.1039/B809636H.

[37] J. W. Morse, F. T. Mackenzie, Aquat. Geochem. 1998, 4, 301-319. DOl: $10.1023 / A: 1009632230875$
[38] Y. Lu, G. Deng, F. Miao, Z. Li, J. Inorg. Biochem. 2003, 96, 487-492. DOI: 10.1016/S0162-0134(03)00251-4.

[39] H. Hu, J. Xue, X. Wen, W. Li, C. Zhang, L. Yang, Y. Xu, G. Zhao, X. Bu, K. Liu, J. Chen, J. Wu, Inorg. Chem. 2013, 52, 13132-13145. DOI: 10.1021/ic402027j.

[40] Y. Lu, J. Guo, Carbohydr. Res. 2006, 34, 683-687. DOI: 10.1016/j. carres.2005.12.011.

[41] Y. Lu, G. Deng, F. Miao, Z. Li, Carbohydr. Res. 2004, 339, 1689-1696. DOI 10.1016/j.carres.2004.04.009.

[42] J. Guo, Y. Lu, J. Carbohydr. Chem. 2010, 29, 10-19. DOI: 10.1080/07328300903477788

[43] Y. Lu, G. Deng, F. Miao, Z. Li, Carbohydr. Chem. 2003, 338, 2913-2919. DOI: 10.1016/j.carres.2003.08.015.

[44] M. Aureliano, P. A. Nolasco, J. J. R. Fraústo da Silva, J. A. L. da Silva, Quim. Nova 2012, 35, 1062-1068. D0I: 10.1590/S0100-40422012000500036.

[45] A. Ricardo, M. A. Carrigan, A. N. Olcott, S. A. Benner, Science 2004, 303, 196. DOI: 10.1126/science.1092464.

[46] Y. Furukawa, T. Kakegawa, Elements 2017, 13, 261-265. DOI: 10.2138/ gselements.13.4.261.

[47] R. Scorei, Orig. Life Evol. Biosph. 2012, 42, 3-17. D0I: 10.1007/s11084-012-9269-2.

[48] T. Furukawa, M. Horiuchi, T. Kakegawa, Orig. Life Evol. Biosph. 2013, 43, 353-361. DOI: 10.1007/s11084-013-9350-5.

[49] E. Šponer, B. G. Sumpter, J. Leszczynski, J. Šponer, M. Fuentes-Cabrera, Chem. Eur. J. 2008, 14, 9990-9998. D01: 10.1002/chem.200800961.

[50] R. Scorei, V. M. Cimpoiaşu, Orig. Life Evol. Biosph. 2006, 36, 1-11. DOI: 10.1007/s11084-005-0562-1.

[51] S. L. Miller, J. Am. Chem. Soc. 1955, 77, 2351-2361. DOI: 10.1021/ja01614a001.

[52] H. Yamada, T. Okamoto, Chem. Pharm. Bull. 1972, 20, 623-624. DOI: 10.1248/cpb.20.623.

[53] H. Yamada, M. Hirobe, K. Higashiyama, H. Takahashi, K. T. Suzuki, Tetrahedron Lett. 1978, 19, 4039-4042. DOI: 10.1016/S0040-4039(01)95134-2.

[54] G. R. Adande, N. J. Woolf, L. M. Ziurys, Astrobiology 2013, 13, 439-453. DOI: 10.1089/ast.2012.0912.

[55] R. Saladino, C. Crestini, G. Costanzo, R. Negri, E. D. Mauro, Bioorganic Med. Chem. 2001, 9, 1249-1253. DOI: 10.1016/S0968-0896(00)00340-0.

[56] H. L. Barks, R. Buckley, G. A. Grieves, E. D. Mauro, N. V. Hud, T. M. Orlando, ChemBioChem 2010, 11, 1240-1243. DOI: 10.1002/cbic.201000074.

[57] R. Saladino, V. Neri, C. Crestini, G. Costanzo, M. Graciotti, E. D. Mauro, J. Am. Chem. Soc. 2008, 130, 15512-15518. D0I: 10.1021/ja804782e.

[58] R. Saladino, C. Crestini, V. Neri, J. R. Brucato, L. Colangeli, F. Ciciriello, E. D. Mauro, G. Costanzo, ChemBioChem 2005, 6, 1368-1374. DOI: 10.1002/ cbic. 200500035

[59] G. J. F. Chittenden, A. W. Schwartz, Nature 1976, 263, 350-351. DOI: $10.1038 / 263350 a 0$

[60] M. H. Studier, R. Hayatsu, E. Anders, Geochim. Cosmochim. Acta 1968, 32, 151-173. DOI: 10.1016/S0016-7037(68)80002-X.

[61] R. Hayatsu, M. H. Studier, A. Oda, K. Fuse, E. Anders, Geochim. Cosmochim. Acta 1968, 32, 175-190. DOI: 10.1016/S0016-7037(68)80003-1.

[62] M. H. Studier, R. Hayatsu, E. Anders, Science 1965, 149, 1455-1459. DOl: 10.1126/science.149.3691.1455

[63] R. Hayatsu, M. H. Studier, S. Matsuoka, E. Anders, Geochim. Cosmochim. Acta 1972, 36, 555-571. DOI: 10.1016/0016-7037(72)90075-0.

[64] E. Anders, R. Hayatsu, Cosmo- and Geochemistry, Topics in Current Chemistry Chemistry 1981, 99, 1-37. Disponível em: ui.adsabs.harvard.edu/ abs/1981coge. conf....1A/abstract.

\section{Catarina Gonçalves}

Catarina Gonçalves, Instituto Superior Técnico (IST), Universidade de Lisboa, é Mestre em Química pelo IST. Desenvolveu este trabalho na sequência da sua tese de mestrado, realizada no Centro de Química Estrutural do IST. catarina.p.goncalves@ist.utl.pt ORCID.org/ 0000-0002-9855-7469 